\title{
Preparation of Mine Filling Material from Steel Slag Mud
}

\author{
Chao Ren ${ }^{1,2}$, Keqing $\mathrm{Li}^{1,2^{*}}$, Wen $\mathrm{Ni}^{1,2}$, Siqi Zhang ${ }^{1,2}$ \\ ${ }^{1}$ School of Civil and Resources Engineering, University of Science and Technology Beijing, Beijing 100083, China \\ ${ }^{2}$ Key Laboratory Ministry of Education for Efficient Mining and Safety of Metal Mines, Beijing 100083, China
}

Corresponding Author Email: lkqing2003@163.com

https://doi.org/10.18280/acsm.430404

Received: 10 May 2019

Accepted: 11 July 2019

\section{Keywords:}

steel slag mud, mine filling material, $X$-ray diffraction (XRD), fourier-transform infrared spectroscopy (FT-IR), nuclear magnetic resonance (NMR)

\begin{abstract}
With the proliferation of wet milling and magnetic separation, a huge amount of steel slag mud has been discharged, waiting to be recycled. To recycle steel slag mud on a largescale, a possible solution is to prepare steel slag and other industrial solid wastes into mine filling materials. In this paper, the steel slag mud is activated through mechanochemical activation, and the mechanical activation laws are explored through X-ray diffraction (XRD) and Fourier-transform infrared spectroscopy (FT-IR). The results show that mechanochemical activation can partially excite the activity of steel slag mud, and that the fineness of steel slag mud is positively correlated with the mechanical performance of the filling material. In addition, the low field nuclear magnetic resonance (NMR) was adopted to analyze how the fineness of steel slag mud affects the porosity distribution of the filling material, and disclose the relationship between fineness and the material strength. The analysis shows that the mine filling materials prepared from steel slag mud, slag and flue gas desulfurization gypsum (FGDG) fully satisfy the required working performance. The research findings lay a theoretical basis for recycling steel slag mud, solves the environmental pollution of this type of industrial solid waste and reduces the filling cost of mine enterprises.
\end{abstract}

\section{INTRODUCTION}

Steel slag is a by-product of crude steel smelting in steel mills. Depending on the smelting method, steel slag may come from converter, electric furnace, or open hearth [1]. In steel slag, the chemical components are mainly $\mathrm{CaO}, \mathrm{MgO}, \mathrm{SiO}_{2}$, $\mathrm{Fe}_{2} \mathrm{O}_{3}, \mathrm{MnO}$ and $\mathrm{Al}_{2} \mathrm{O}_{3}$, and the main minerals include dicalcium silicate, tricalcium silicate, calcium forsterite, the $\mathrm{RO}$ phase, free $\mathrm{CaO}$, etc. [2]. The minerals like calcium silicate give steel slag a certain hydraulicity [3], making it suitable to be applied in building materials. For instance, steel slag often serves as a mineral admixture to prepare steel slag cement and concrete. With good durability and permeability, the steel slag can replace the traditional gravel aggregate for road engineering. In addition, steel slag can also be used as a soil conditioner in agriculture and a heavy metal ion adsorbent in wastewater treatment.

Despite being a waste product, steel slag still contains a large amount of metal iron. To recover more magnetic irons from steel slag, many Chinese enterprises began to separate iron from steel slag through wet milling and magnetic separation. The separation creates huge piles of steel slag mud. Then, the mud is hydrated through water washing, and becomes less cementitious. The large amount of sludge will seriously harm the environment and occupy a wide area of land. This calls for effective technical measures to make comprehensive use of steel slag mud. However, the relevant research is far from enough.

The foreign studies on industrial solid wastes like steel slag started early and produced fruitful results. For example, Chand et al. [4] evaluated the heavy metal leaching potential of LinzDonawitz (LD) slag in steel industry through varied test methods. Chaurand et al. [5] examined the leaching behavior of chromium and vanadium in basic oxygen furnace (BOF) slag, revealing that: chromium is released in a small amount, remains in the initial trivalent state, and shows a low toxicity even if it is leached. Eloneva et al. [6] discussed the suitability of a carbonization route that produces carbonates with blastfurnace slag through acetic acid leaching. Huijgen et al. [7] identified the carbonization costs of wollastonite and steel slag as 102 and $77 € /$ ton $\mathrm{CO}_{2}$, and talked about the suitability of the carbonation route to produce carbonates with steel slag. Through accelerated carbonization, Polettini et al. [8] enhanced the ability of the BOF steel slag to capture $\mathrm{CO}_{2}$, and increased the $\mathrm{CO}_{2}$ absorption to $12 \sim 14 \%$ (wt). Asi [9] found that the asphalt concrete containing $30 \%$ steel slag has a greater skid number than any other asphalt mixtures. Focusing on concrete admixture for pavement, Kourounis et al. [10] used the steel slag to partially replace natural coarse aggregate, measured the compressive, flexural and tensile strengths of the product, and compared the product with traditional concrete. Manso et al. [11] investigated the compressive strength, water permeability, ecological safety and antifreeze performance of the concrete containing electric arc furnace (EAF) slag. Monshi et al. [12] produced Portland cement with steel slag and limestone, and found that blending $10 \%$ extra iron slag to a cement composed of $49 \%$ iron slag, $43 \%$ calcined lime, and $8 \%$ steel slag keeps the compressive strength of concrete above standard values for type I ordinary Portand cement. Yüksel [13] explored the strength and durability changes of concrete or mortar materials in different mix ratios, adopted these materials as substitutes for aggregate or cement, and combined them with ground granular blast furnace slag and steel slag. Maslehuddin et al. [14] discovered that steel slag 
aggregate concrete is more durable than gravel concrete. Beshr et al. [15] compared how the compressive strength, tensile strength and elastic modulus of high-strength concrete are affected by four coarse aggregates, namely, limestone, dolomite, quartzite and steel slag. Chukwudi and Okorie [16] treated ceramic tiles with kaolinite clay and steel slag, revealing that the sample tiles containing $20-60 \mathrm{wt} \%$ steel slag have good performance.

Chinese scholars have also made some progress on the research of steel slag and other industrial solid wastes. For instance, Ortiz et al. [17] probed into the $\mathrm{Ni}^{2+}$ in the wastewater of converter slag treatment. Hou et al. [18] evaluated the adsorption performance of water-cooled steel slag on $\mathrm{Pb}^{2+}$ in wastewater. Ma et al. [19] prepared a clinker-free solid waste concrete with a composite cementitious material, containing steel slag, slag and flue gas desulfurization gypsum (FGDG), and concluded that the clinker-free concrete has the optimal content of steel slag powder, and meets the $3 \mathrm{~d}$ strength $(22.56 \mathrm{MPa})$ and $28 \mathrm{~d}$ strength $(55.97 \mathrm{MPa})$ required for $\mathrm{C} 50$ grade concrete when the ratio of steel slag to slag in the cementitious material is $1: 2.5$. Wu et al. [20] screened iron tailings from Minyun District, Beijing, reserved coarse tailings for the preparation of coarse aggregate, and mechanically ground or calcinated fine tailings, creating a cementitious material for high-strength concrete. Under a certain water-tobinder ratio, the concrete samples with $70 \%$ tailings reached the $28 \mathrm{~d}$ strength of $89 \mathrm{MPa}$ or $99 \mathrm{MPa}$.

To sum up, the recycling of steel slag is increasing mature. However, there is little report on the mud produced from steel slag through wet milling and magnetic separation. In this case, it is very meaningful to explore the largescale recycling of steel slag mud. Drawing on the existing studies at home and abroad and the similar hydraulicity between steel slag mud and steel slag, this paper tentatively explores the preparation of mine filling materials with steel slag mud and multiple solid wastes, using the steel slag-slag-FGDG cementitious material. Besides, the hydraulicity evolution of steel slag mud was studied through mechanochemical activation, laying a theoretical basis for largescale recycling of steel slag mud.

Firstly, the physicochemical properties of the raw materials were analyzed in details. Next, the steel slag mud was activated mechanochemically and examined in depth. After that, the steel slag mud samples ground for different periods were analyzed through X-ray diffraction (XRD), Fouriertransform infrared spectroscopy (FT-IR), etc. Moreover, the low field nuclear magnetic resonance (NMR) was adopted to analyze the internal pore evolution of the prepared filling materials. Finally, the recyclability of steel slag mud was confirmed based on the results.

\section{MATERIALS AND METHODS}

\subsection{Raw materials}

The steel slag mud was obtained from Shougang Qian'an Iron and Steel Co., Ltd. The slag (micro powder) was provided from Hebei Jinxi Iron \& Steel Co., Ltd. The FGDG was collected from Qian'an Thermal Power Plant. The chemical components of the three materials are listed in Table 1.

Table 1. Chemical components of raw materials

\begin{tabular}{ccccccccc}
\hline Raw materials & $\mathbf{C a O}$ & $\mathrm{SiO}_{2}$ & $\mathrm{Al}_{2} \mathrm{O}_{3}$ & $\mathbf{M g O}$ & $\mathrm{Fe}_{2} \mathrm{O}_{3}$ & $\mathrm{TiO}_{2}$ & $\mathrm{MnO}_{3}$ & $\mathrm{SO}_{3}$ \\
\hline Slag & 46.45 & 21.69 & 15.51 & 8.42 & 2.50 & 1.86 & 0.70 & 0.85 \\
Steel slag mud & 35.68 & 10.65 & 2.51 & 4.41 & 38.51 & 0.80 & 4.35 & 0.15 \\
FGDG & 39.64 & 1.87 & 0.52 & 0.72 & 0.51 & 0.06 & 0.01 & 33.57 \\
\hline
\end{tabular}

(1) Steel slag mud. The XRD pattern of the steel slag mud is shown in Figure 1. It can be seen that the highly alkaline steel slag mud mainly contains $\beta$-dicalcium silicate $\left(2 \mathrm{CaO} \cdot \mathrm{SiO}_{2}, \beta \mathrm{C}_{2} \mathrm{~S}\right), \gamma$-dicalcium silicate $\left(2 \mathrm{CaO} \cdot \mathrm{SiO} 2, \gamma \mathrm{C}_{2} \mathrm{~S}\right)$, tricalcium silicate $(3 \mathrm{CaO} \cdot \mathrm{SiO} 2, \mathrm{C} 3 \mathrm{~S})$ and dicalcium ferrite $\left(2 \mathrm{CaO} \cdot \mathrm{Fe}_{2} \mathrm{O}_{3}, \mathrm{C}_{2} \mathrm{~F}\right)$, the $\mathrm{RO}$ phase of iron-bearing solid solutions, $\mathrm{Ca}(\mathrm{OH})_{2}$ and a few amount of $\mathrm{CaCO}_{3}$. The various minerals in the steel slag mud result in the multiple overlapping diffraction peaks in the XRD pattern.

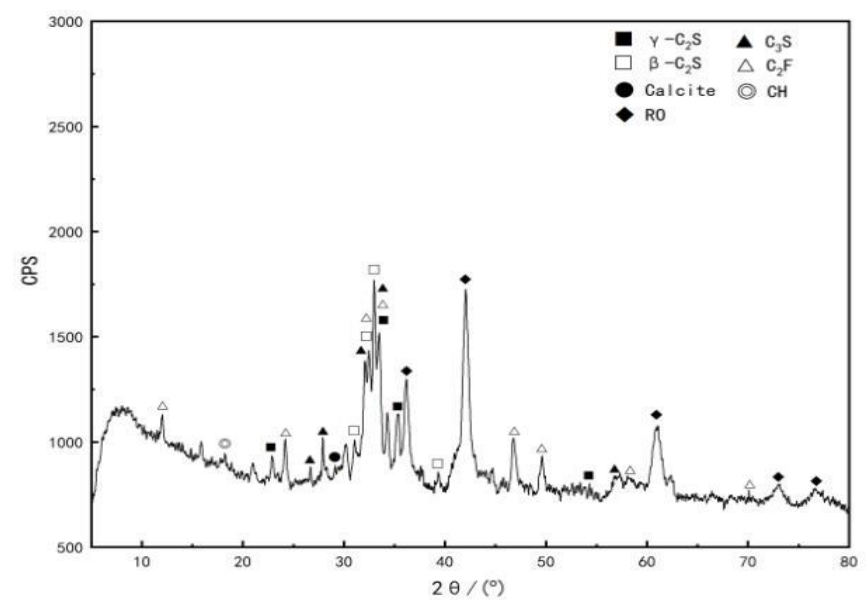

Figure 1. XRD pattern of the steel slag mud
(2) Slag and the FGDG. The XRD patterns of slag and the FGDG are presented in Figures 2 and 3, respectively. In Figure 2 , there is no obvious crystallization peak but a bulge at around $30^{\circ}$, indicating that the main content of slag is gehlenite $\left(\mathrm{Ca}_{2} \mathrm{Al}\right.$ $\left.\left[\mathrm{AlSiO}_{7}\right]\right)$. Meanwhile, the FGDG is mainly composed of calcium sulfate dihydrate $\left(\mathrm{CaSO}_{4} \cdot 2 \mathrm{H}_{2} \mathrm{O}\right)$.

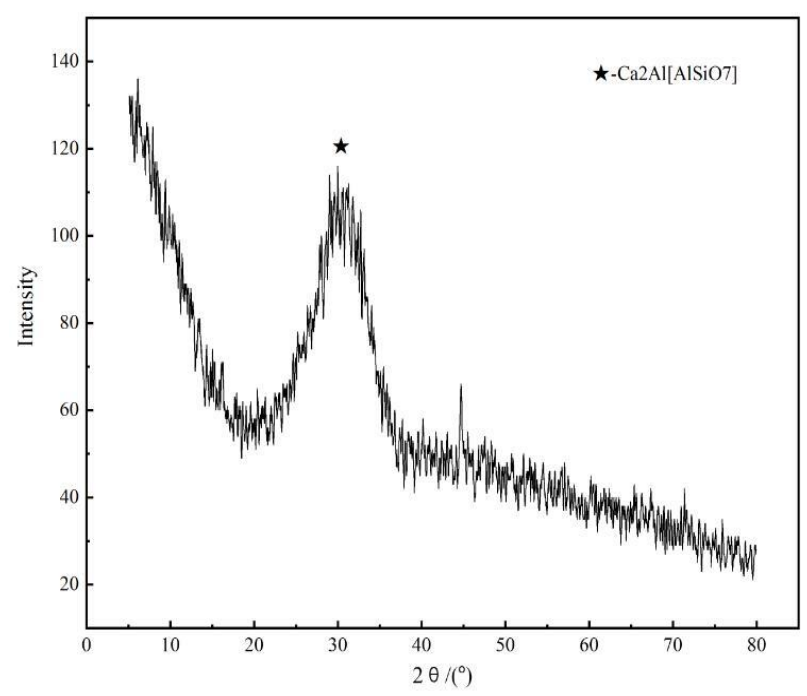

Figure 2. XRD pattern of slag 


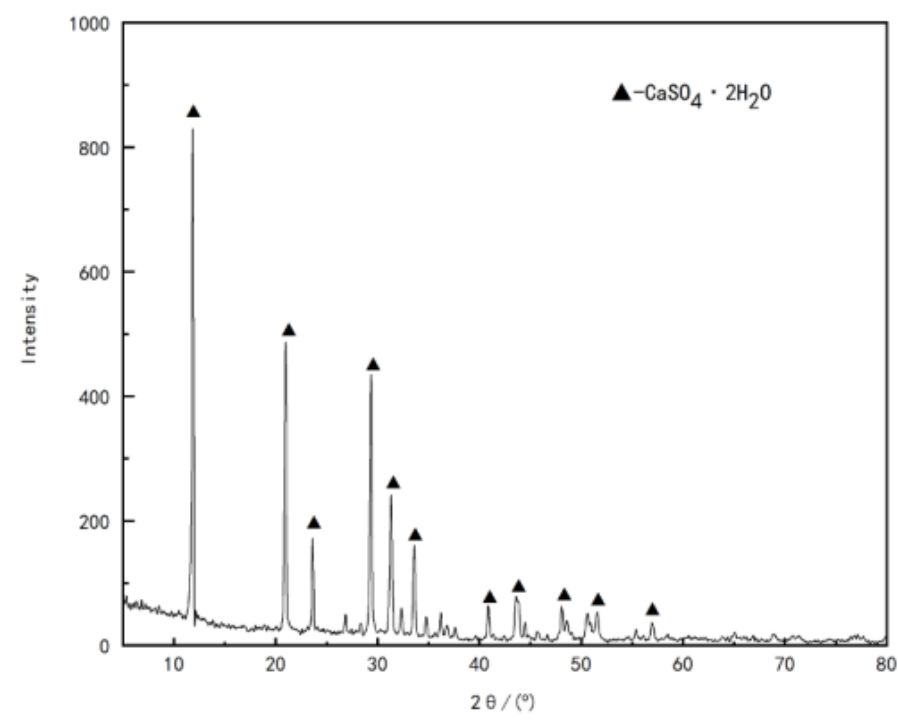

Figure 3. XRD pattern of the FGDG

\subsection{Instruments}

The X-ray fluorescence (XRF) spectrometry was performed on an XRF-1800 Sequential X-ray Fluorescence Spectrometer (Shimadzu Corp., Japan). The XRF spectrometry data were analyzed in the chemical analysis lab of University of Science and Technology Beijing (USTB).

The X-ray diffraction analysis (XRD) was conducted on a $\mathrm{D} /$ Max-RC X-ray powder diffractometer (Rigaku, Japan) using $\mathrm{Cu}-\mathrm{K} \alpha \mathrm{X}$-ray (wavelength: $\lambda=1.5418 \AA$ ). The tube voltage and tube current are $40 \mathrm{kV}$ and $100 \mathrm{~mA}$, respectively.

The Fourier-transform infrared spectroscopy (FT-IR) was implemented on an FTIR-8400s Fourier transform infrared spectrometer (Shimadzu Corp., Japan).

The nuclear magnetic resonance (NMR) was carried out on a MesoMR23-060H-I NMR analysis and imaging system (Niumag Corp., China), using permanent magnets. The magnetic field strength, main instrument frequency, probe coil diameter and effective detection ranges are $0.5 \pm 0.05 \mathrm{~T}$, $21.3 \mathrm{MHz}, 60 \mathrm{~mm}$ and $\varnothing 60 \mathrm{~mm} \times \mathrm{H} 60 \mathrm{~mm}$, respectively.

\subsection{Test methods}

The steel slag mud, slag and the FGDG were placed in an oven and dried to less than $1 \%$ of water. The dried materials were ground by an $\mathrm{SM} \varphi 500 \times 500$ cement test grinder. The slag was ground until its specific surface area (SSA) reached $550 \mathrm{~m}^{2} / \mathrm{kg}$, and the FGDG was ground until its SSA reached $450 \mathrm{~m}^{2} / \mathrm{kg}$. The steel slag mud was ground for different durations, i.e. $20 \mathrm{~min}, 40 \mathrm{~min}, 60 \mathrm{~min}, 80 \mathrm{~min}, 100 \mathrm{~min}$ and $120 \mathrm{~min}$. The SSA and particle size of the steel slag mud ground for each duration were analyzed in details.

The steel slag tail mud with different fineness was mixed with the ground slag and the ground FGDG into the cementitious material at the mix ratio of $55: 30: 15$. The slurry content was $72 \%$ and the binder-to-sand ratio was $1: 4$. The materials were mixed evenly in a cement mortar mixer, poured in a $40 \mathrm{~mm} \times 40 \mathrm{~mm} \times 160 \mathrm{~mm}$ mold, and cured to the preset age. Then, the specimens of mine filling materials were subjected to compressive strength measurement.

\section{ANALYSIS OF TEST RESULTS}

\subsection{Particle size distributions of steel slag muds at different grinding durations}

In the grinding process, the particle size of steel slag mud gradually decreases and falls into an increasingly small distribution interval. The particle size distributions of steel slag mud after being ground for $20 \mathrm{~min}, 40 \mathrm{~min}, 60 \mathrm{~min}, 80 \mathrm{~min}$, $100 \mathrm{~min}$ and $120 \mathrm{~min}$ are presented in Figures 4(a) (f), respectively. As shown in Figure 4, the particle size of steel slag mud being ground for different durations obeyed polarized distribution, rather than lognormal distribution. With the growth in grinding duration, the polarization of particle size distribution gradually increased and then decreased. This trend is mainly attributable to the significant difference in grindability between the varied minerals of steel slag mud. In addition, the longer the grinding duration, the lower the peak particle size of steel slag mud, indicating that the dominance of medium-coarse particles in steel slag mud is gradually replaced by medium-fine particles through the mechanical grinding.

As shown in Figures 4(a) (b), in the first 20min of grinding, the particle size of steel slag mud started to decrease rapidly, but more than half of the mud particles were still larger than $10 \mu \mathrm{m}$; after $40 \mathrm{~min}$ of grinding, the number of greater-than$10 \mu \mathrm{m}$ particles gradually reduced. As shown in Figures 4(c) (d), many submicron particles appeared in the steel slag mud, and their proportion in the mud continued to increase. As shown in Figures 4(e) (f), further extension of the grinding duration slowed down the growth in the number of smallerthan- $10 \mu \mathrm{m}$ particles in the steel slag mud, and stabilized the distribution interval of particle size. The above results show that the longer the grinding duration, the smaller the particle size of steel slag mud. However, many submicron and nanosized particles will emerge and agglomerate after continued grinding. As a result, there was no significant increase in the number of fine particles, after the grinding lasted more than $100 \mathrm{~min}$.

The characteristic particle sizes of steel slag mud being ground for different durations were analyzed. The results were recorded in Table 2, and observed to disclose the change laws of the particle sizes at $\mathrm{D}_{10}, \mathrm{D}_{50}$ and $\mathrm{D}_{90}$, respectively, the cumulative particle size distribution of $10 \%, 50 \%$ and $90 \%$ in volume percentage [21]. $D_{10}$ and $D_{90}$ describe the cumulative distributions of fine particles and large particles, respectively. The $D_{10}$ value is negatively correlated with the number of fine particles, while the $D_{90}$ value is positively correlated with the number of large particles. $\mathrm{D}_{50}$ reflects the mean particle size of steel slag mud.

It can be seen in Table 2 that the characteristic particle sizes of steel slag mud were not always negatively correlated with the grinding duration. Specifically, the $\mathrm{D}_{50}$ value dropped from $16.41 \mu \mathrm{m}$ to $6.77 \mu \mathrm{m}$, revealing that the mean particle size of steel slag mud gradually declined with the extension of grinding duration. This means the number of fine particles increased while that of large particles decreased. Both $\mathrm{D}_{10}$ and $D_{90}$ plunged deeply before $100 \mathrm{~min}$ and slightly rebounded after that time point: the $\mathrm{D}_{10}$ value firstly decreased from $2.40 \mu \mathrm{m}$ to $1.33 \mu \mathrm{m}$, and then grew to $1.35 \mu \mathrm{m}$; the $\mathrm{D}_{90}$ value firstly dropped from $55.01 \mu \mathrm{m}$ to $33.16 \mu \mathrm{m}$, and then rose to $34.20 \mu \mathrm{m}$. The slight increase in $\mathrm{D}_{10}$ and $\mathrm{D}_{90}$ after $100 \mathrm{~min}$ occurs due to the agglomeration of steel slag mud particles after excessively long grinding. 

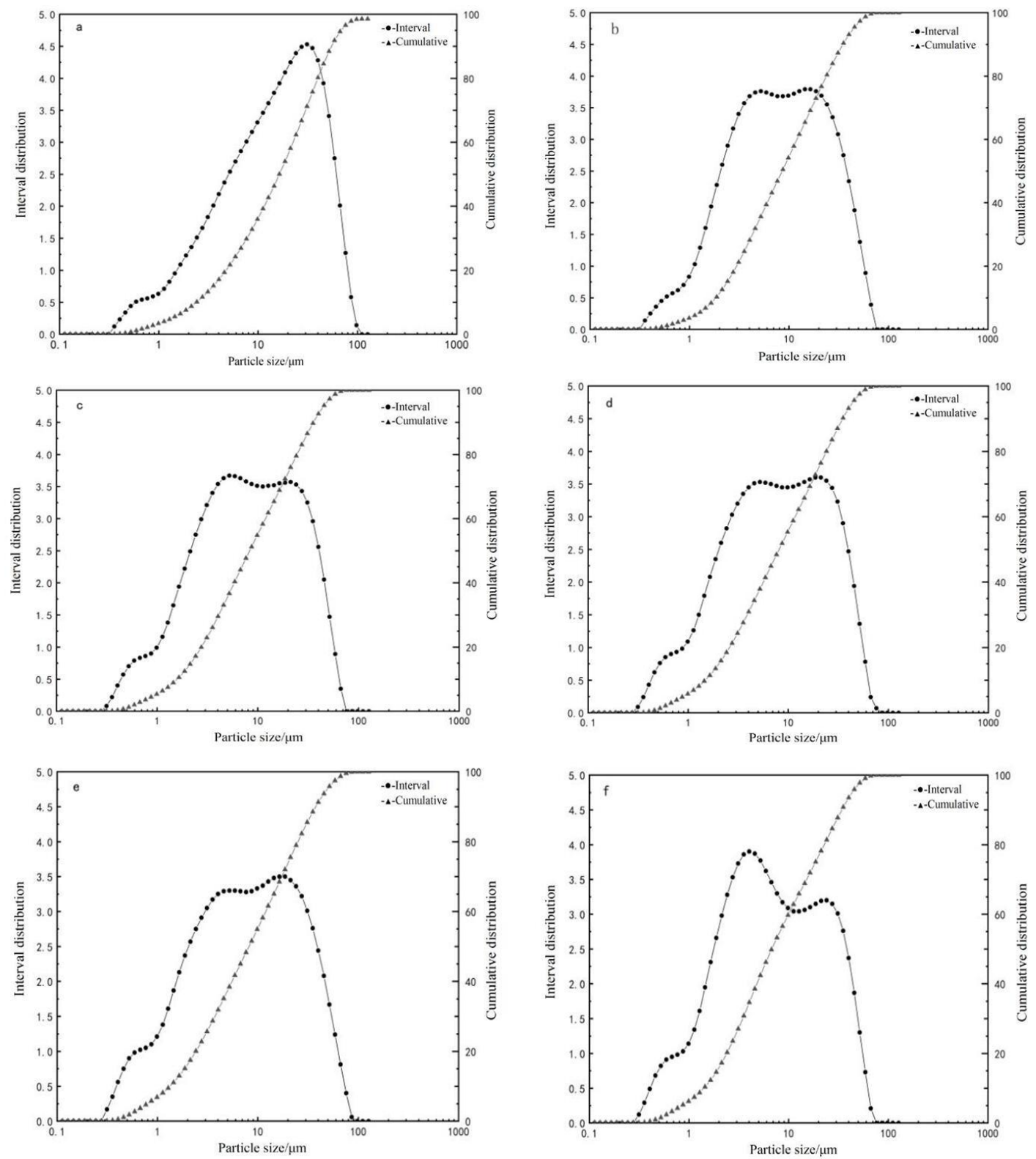

Figure 4. Particle size distributions of steel slag mud at different grinding durations

Table 2. Characteristic particle sizes of steel slag mud being ground for different durations

\begin{tabular}{cccc}
\hline \multirow{2}{*}{$\begin{array}{c}\text { Grinding } \\
\text { duration/min }\end{array}$} & \multicolumn{3}{c}{$\begin{array}{c}\text { Characteristic particle } \\
\text { size/ } \boldsymbol{\mu m}\end{array}$} \\
\cline { 2 - 4 } & $\mathbf{D}_{\mathbf{1 0}}$ & $\mathbf{D}_{\mathbf{5 0}}$ & $\mathbf{D}_{\mathbf{9 0}}$ \\
\hline 20 & 2.40 & 16.41 & 55.01 \\
\hline 40 & 1.84 & 8.52 & 34.83 \\
\hline 60 & 1.58 & 8.30 & 33.26 \\
\hline 80 & 1.49 & 7.85 & 32.96 \\
\hline 100 & 1.33 & 7.32 & 33.16 \\
\hline 120 & 1.31 & 6.77 & 34.20 \\
\hline
\end{tabular}

\subsection{XRD analysis on steel slag mud at different grinding durations}

In addition to particle size reduction, steel slag mud undergoes changes in crystal structure and surface physicochemical properties through grinding. Due to mechanical grinding, more and more $\mathrm{Ca}-\mathrm{O}$, Si-O and $\mathrm{Fe}-\mathrm{O}$ broken bonds appear in the crystal structure. The crystal lattice is thus distorted, forming an amorphous structure on particle surface. This is because the grinding energy is partially converted into the internal energy and surface energy of the particles, with the growing SSA of steel slag mud [22].

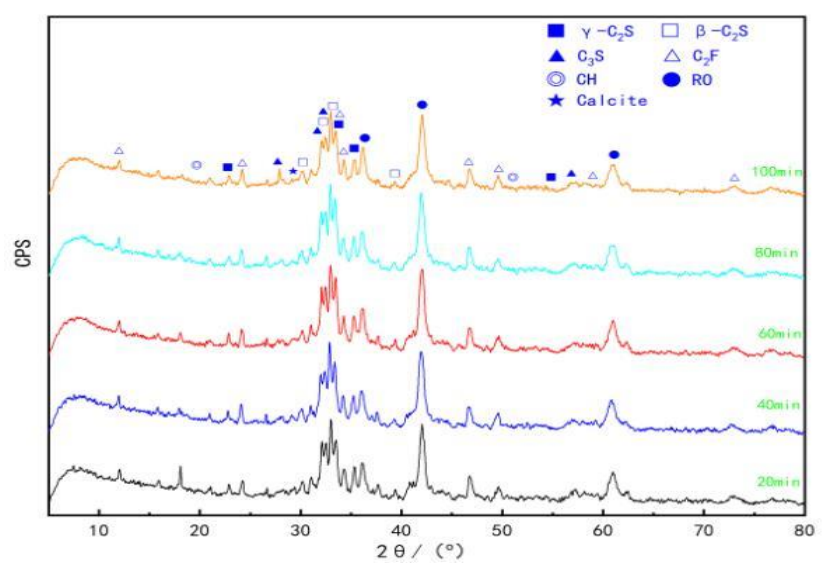

Figure 5. XRD patterns of steel slag mud at different grinding durations 
Figure 5 displays the XRD patterns of steel slag mud at different grinding durations. Obviously, the diffraction peaks at different angles did not change with the grinding duration. Thus, increasing the grinding duration cannot promote the formation of new phase in steel slag mud. On diffraction peak intensity, after 100min of grinding, the diffraction peaks on the (102) and (110) crystal planes of $\mathrm{CH}^{-}$almost disappeared, those on the crystal planes of $\gamma-\mathrm{C}_{2} \mathrm{~S}$ and $\beta-\mathrm{C}_{2} \mathrm{~S}$ were greatly weakened, and those of $\mathrm{CaO}, \mathrm{C}_{3} \mathrm{~S}$ and $\mathrm{RO}$ phase also became shorter, wider and flatter. These phenomena indicate that, under mechanical activation, some minerals of steel slag mud witnessed the distortion of crystal lattice and amorphous change in crystal structure.

\subsection{FT-IR analysis on steel slag mud at different grinding durations}

The steel slag mud was subjected to infrared analysis after being ground for $20 \mathrm{~min}, 60 \mathrm{~min}$ and $100 \mathrm{~min}$. Figure 6 compares the FT-IR patterns of steel slag muds with different fineness. It can be seen that, despite the difference in fineness, the steel slag muds were basically the same in the positions of bands and characteristic peaks.

In Figure 6, the absorption characteristic peaks at $516 \mathrm{~cm}^{-1}$ are resulted from the bending vibration of the $\mathrm{Si}-\mathrm{O}-\mathrm{Si}$ bond. The bands between $800 \mathrm{~cm}^{-1}$ and $1,100 \mathrm{~cm}^{-1}$ belong to the Si$\mathrm{O}$ vibration band. The typical C-S-H characteristic peaks here are caused by the asymmetric tensile vibration of $\mathrm{Si}-\mathrm{O}$. The bands between $1,412 \mathrm{~cm}^{-1}$ and $1,477 \mathrm{~cm}^{-1}$ represents the asymmetric vibration band of $\mathrm{CO}_{3}{ }^{2-}$, which come from the carbonization of the steel slag mud during the hydration process. The bands at $3,645 \mathrm{~cm}^{-1}$ are produced by the stretching vibration of the $\mathrm{O}-\mathrm{H}$ bond in the $\mathrm{Ca}(\mathrm{OH})_{2}$, which is the hydration product of steel slag mud.

In Figure 6, the typical characteristic peaks became sharper with the increase of the fineness of steel slag mud. A possible reason lies in the soaring number of nano-sized particles in the mud and the continued growth in the number of surface atomic groups, which both occurred with the extension of the grinding duration.

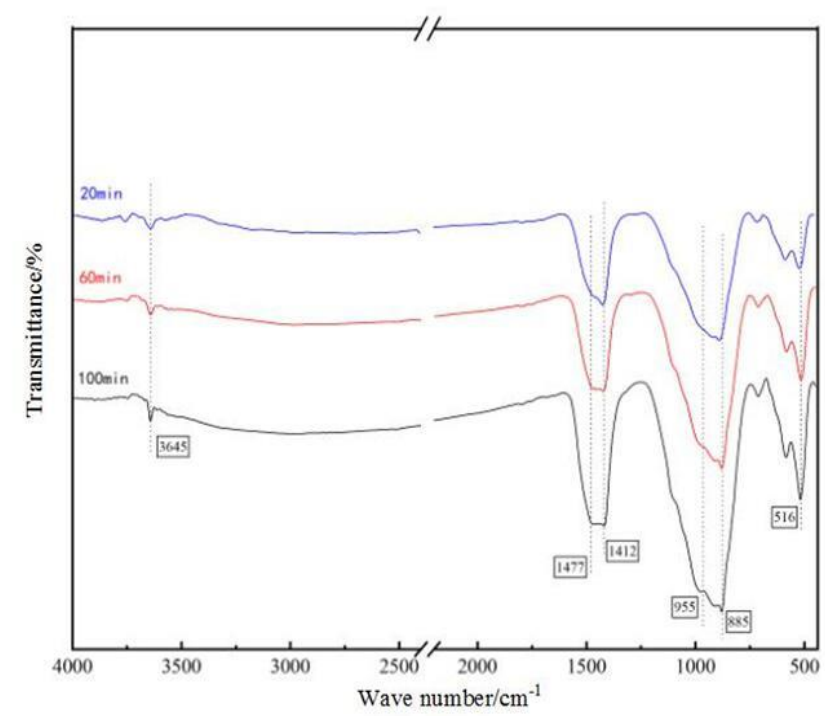

Figure 6. FT-IR patterns of steel slag mud at different grinding durations

\subsection{Mechanical analysis on steel slag mud at different} grinding durations

Figure 7 illustrates the compressive strengths of the prepared filling material at different grinding durations. It can be seen that, with the growth in grinding duration, the steel slag mud became increasingly fine. For the prepared specimens, their compressive strengths were all positively correlated with fineness, whichever the curing age.

After 80 minutes of mechanical grinding, the steel slag mud was fully activated, which greatly enhances the specimen strength. This is because a long grinding excites the active components (e.g. $\mathrm{C}_{2} \mathrm{~S}$ and $\mathrm{C}_{3} \mathrm{~S}$ ) not yet hydrated in steel slag mud. Steel slag mud is the product of wet milling and mechanical separation. The active components originally in the steel slag have already been partially hydrated. Hence, the steel slag mud is less active than the steel slag, leading to the low weak strength of the mud system. Therefore, an important way to prepare mine filling material from steel slag mud is to fully activate the cementitious property of the mud through mechanochemical activation.

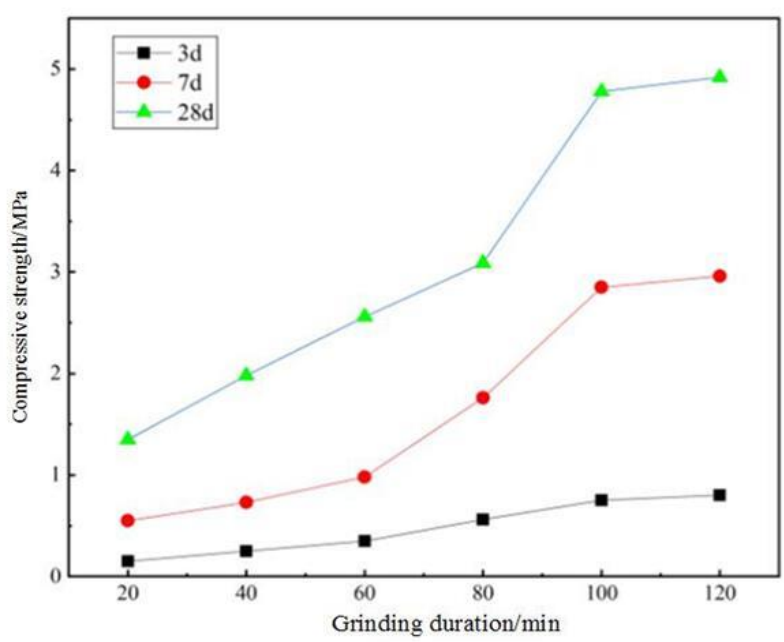

Figure 7. Effects of steel slag mud fineness on mechanical performance of the filling material

3.5 NMR-based analysis on the effects of steel slag mud fineness on the porosity distribution law of the prepared filling material

The NMR analysis and imaging system was employed to measure the spin echo amplitude of the Carr-PurcellMeiboom-Gill (CPMG) sequence, aiming to detect the attenuation of transverse magnetization vector and the unrecoverable dispersed phase. The time constant of transverse magnetization attenuation is called the transverse relaxation time $T_{2}$. The porosity distribution of each type of pores can be characterized based on the ratio of the signal intensity of the water in each pore to that in all the pores and the porosity of the specimen. The amplitude of the spin echo attenuation can be accurately fitted by adding up a set of exponential attenuation curves, each with a unique attenuation constant. The set of all attenuation constants is the $T_{2}$ distribution.

In this paper, the $T_{2}$ distribution maps of the filling materials prepared from steel slag muds ground for different durations are obtained through CPMG tests, which intuitively display the porosity distribution of mine filling materials. Then, the 
porosity distribution law was explored to disclose the effects of grinding duration on the mechanical performance of the filling materials.

Figures $8 \sim 11$ show the $\mathrm{T}_{2}$ distribution maps of steel slag mud at different grinding durations. It can be seen that the $\mathrm{T}_{2}$ distribution map of the filling material prepared from steel slag mud ground for whichever duration had two clear relaxation peaks. The primary peak was relatively large and worthy of detailed analysis. Therefore, the author explored the primary peak distribution law of the filling materials prepared from steel slag muds ground for different durations and cured for different ages. In general, the primary peaks in the $T_{2}$ maps of these filling materials fell between $0.5 \mathrm{~ms}$ and $8 \mathrm{~ms}$, and their areas decreased with the growth in the curing age. These trends can be explained by the nature of the hydration of the filling materials: the physically-bound water is converted to chemically-bound water.

With the increase of curing age, the $\mathrm{T}_{2}$ distribution of the

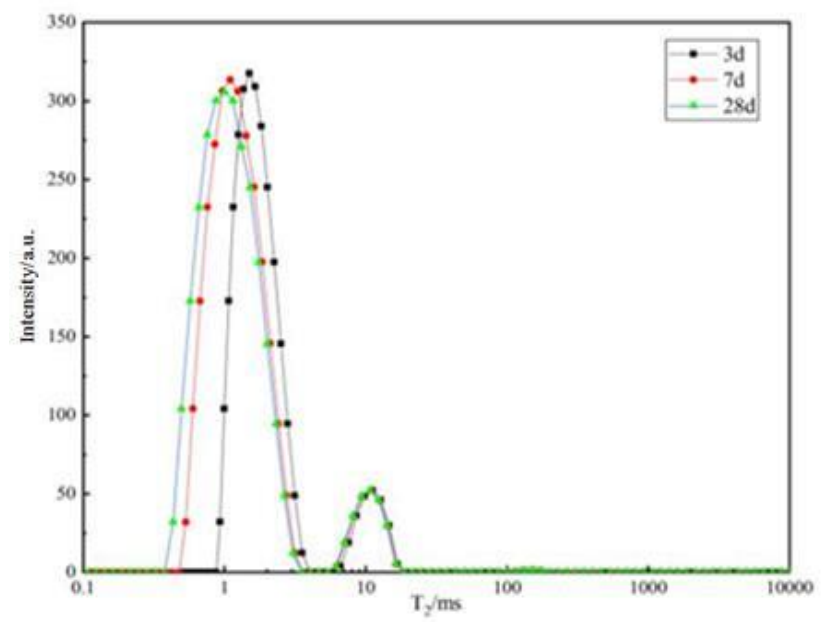

Figure 8. $\mathrm{T}_{2}$ distribution map after $20 \mathrm{~min}$ of grinding

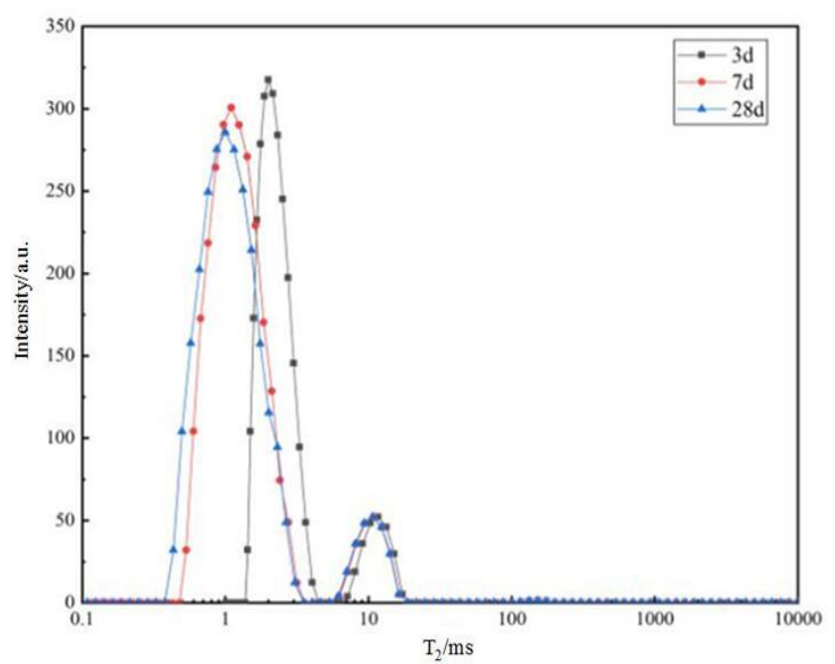

Figure 10. $\mathrm{T}_{2}$ distribution map after $80 \mathrm{~min}$ of grinding

Figures 12 14 present the $\mathrm{T}_{2}$ distribution maps of the filling materials prepared from steel slag muds ground for different durations and cured to the same age. It is obvious that these filling materials had similar $\mathrm{T}_{2}$ distributions: two relaxation peaks appeared between $0.1 \mathrm{~ms}$ and $10 \mathrm{~ms}$ and covered similar areas. At the age of $3 \mathrm{~d}$, the filling materials prepared from steel slag muds ground for different durations saw insignificant changes in $\mathrm{T}_{2}$ distribution. However, the longer the grinding filling materials prepared from steel slag muds ground for different durations shifted to the left. For the filling materials prepared from muds ground for $20 \mathrm{~min}$, the area and displacement of the $T_{2}$ primary peaks were not obvious, indicating that the mud activity is not fully released and the filling material is not highly hydrated in the early phase of grinding. When the grinding duration increased to $40 \mathrm{~min}$, the $\mathrm{T}_{2}$ primary peaks were clearly displaced from those after $20 \mathrm{~min}$ of grinding. Thus, the increase of grinding duration improves the activity of steel slag mud. At the grinding duration of $80 \mathrm{~min}$, the displacement of $\mathrm{T}_{2}$ primary peaks were even more significant. This means the mud fineness continues to grow through grinding, which fully activates the mud and speeds up the hydration. After the grinding lasted $100 \mathrm{~min}$, the $\mathrm{T}_{2}$ primary peaks of the filling materials at all curing ages had significant displacement, an evidence of effective mechanochemical activation and accelerated hydration rates for all filling materials.

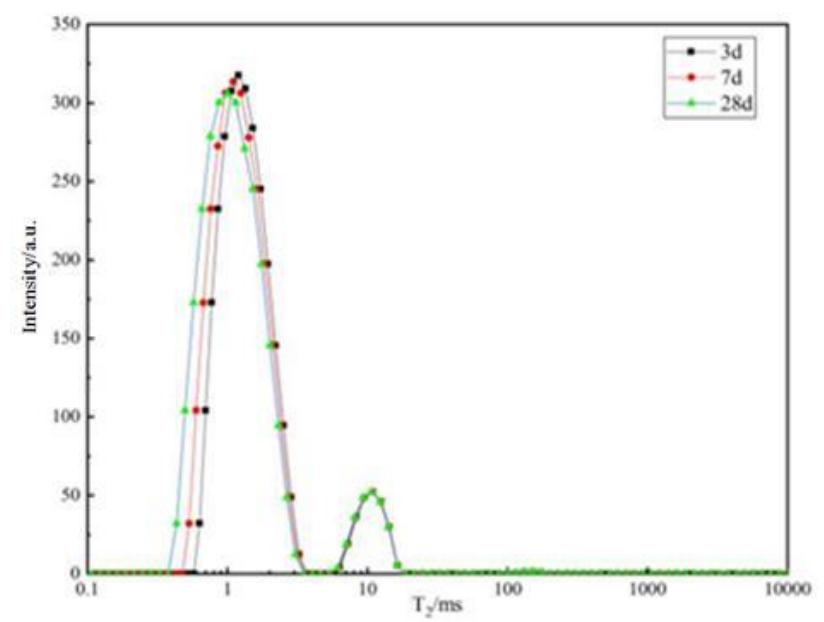

Figure 9. $\mathrm{T}_{2}$ distribution map after $40 \mathrm{~min}$ of grinding

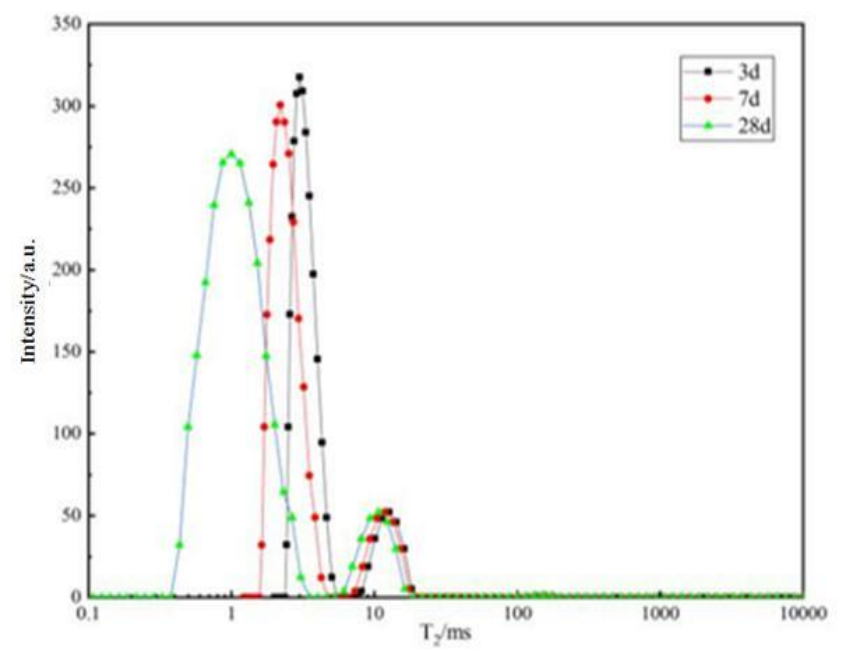

Figure 11. $T_{2}$ distribution map after $100 \mathrm{~min}$ of grinding

duration, the closer the $\mathrm{T}_{2}$ was to the relatively small relaxation time. The same laws were observed for the filling materials at the age of $7 \mathrm{~d}$ and $28 \mathrm{~d}$. The results show that, with the growth in curing age, the longer the grinding duration, the more thorough the hydration of steel slag mud, the smaller the particle size and the better mechanical performance of the filling material. 


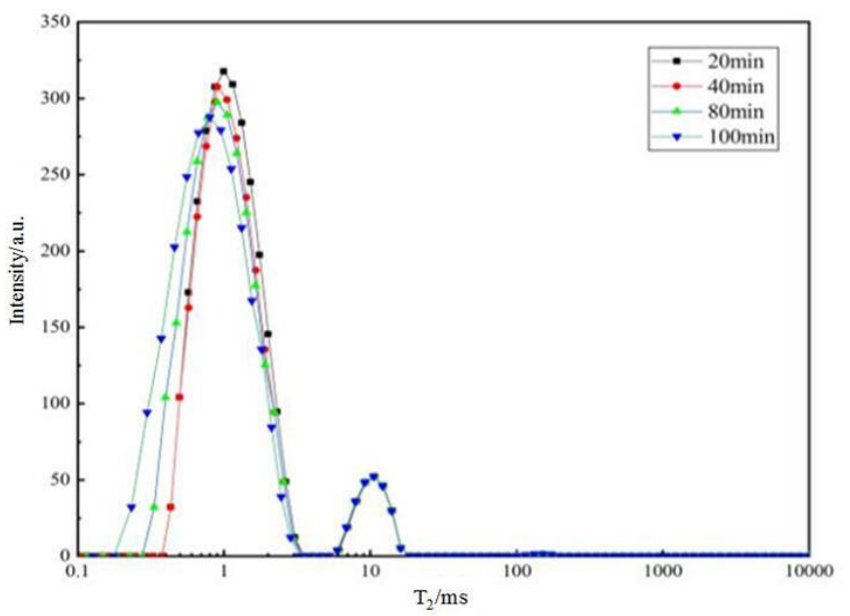

Figure 12. $T_{2}$ distribution map for $3 d$ filling materials prepared from steel slag muds ground for different durations

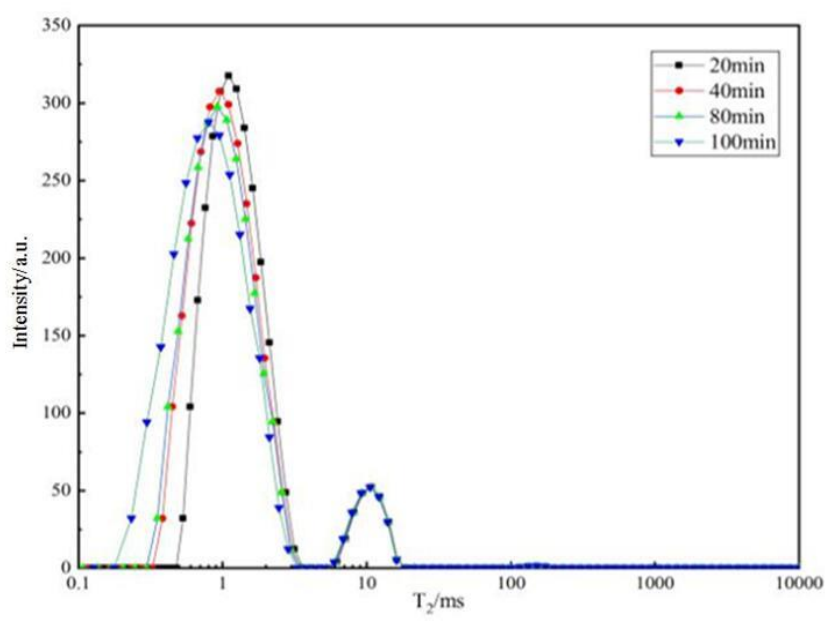

Figure 13. $T_{2}$ distribution map for $7 d$ filling materials prepared from steel slag muds ground for different durations

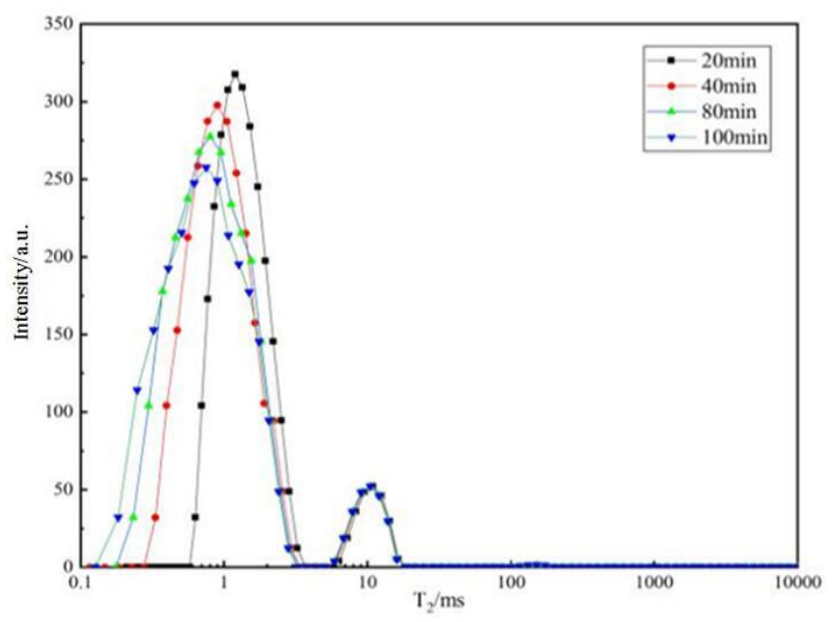

Figure 14. $T_{2}$ distribution map for $28 \mathrm{~d}$ filling materials prepared from steel slag muds ground for different durations

\section{CONCLUSIONS}

(1) Due to the weak cementitious property of steel slag mud, the active components like $\mathrm{C}_{2} \mathrm{~S}$ and $\mathrm{C}_{3} \mathrm{~S}$ in steel slag mud can be effectively stimulated through mechanochemical activation.
This treatment makes steel slag mud a major raw material for mine filling material, laying the basis for largescale recycling of steel slag mud.

(2) The filling material enjoys the best mechanical performance, when the steel slag mud is ground for $80 \sim 100 \mathrm{~min}$ to the SSA of $520 \mathrm{~m}^{2} / \mathrm{kg}$. The grinding duration should not surpass $100 \mathrm{~min}$, because more and more micron and nanosized particles appear and agglomerate in the mud.

(3) The NMR-based analysis shows that, the longer the grinding duration, the finer the steel slag mud, the faster and more thorough the hydration of the filling material. Thus, a long grinding of steel slag mud helps to reduce the particle size and enhance the better mechanical performance of the filling material.

\section{REFERENCES}

[1] Ahmadi, P.F., Ardeshir, A., Ramezanianpour, A.M., Bayat, H. (2018). Characteristics of heat insulating clay bricks made from zeolite, waste steel slag and expanded perlite. Ceramics International, 44(7): 7588-7598. https://doi.org/10.1016/j.ceramint.2018.01.175

[2] Motz, H., Geiseler, J. (2001). Products of steel slags an opportunity to save natural resources. Waste Management, 21(3): 285-293. https://doi.org/10.1016/S0956-053X(00)00102-1

[3] Wang, Q., Mengyuan, L.I., Shi, M. (2014). Hydration properties of cement-steel slag-ground granulated blast furnace slag complex binder. Journal of the Chinese Ceramic Society, 42(5): 629-634. https://doi.org/10.7521/j.issn.0454-5648.2014.05.12

[4] Chand, S., Paul, B., Kumar, M. (2016). Short-term leaching study of heavy metals from LD slag of important steel industries in Eastern India. Journal of Material Cycles \& Waste Management, 19(2): 1-12. https://doi.org/ 10.1007/s10163-016-0486-z

[5] Chaurand, P., Rose, J., Proux, O., Hazemann, J.L., Briois, V., Salome, M., Susini, J., Ferrasse, J.H., Borschneck, D., Bottero, J.Y. (2007). Environmental impact of steel slag reused as aggregates in road manufacturing: molecular mechanisms of chromium and vanadium release. AIP Conference Proceedings, 882(1): 199-199. https://doi.org/10.1063/1.2644473

[6] Zevenhoven, R., Eloneva, S., Teir, S. (2006). Chemical fixation of $\mathrm{CO}_{2}$ in carbonates: Routes to valuable products and long-term storage. Catalysis Today, 115(1): 73-79. https://doi.org/10.1016/j.jenvman.2015.11.042

[7] Huijgen, W.J.J. (2007). Carbon dioxide sequestration by mineral carbonation. Wur Wageningen Ur, 3(8): 13. https://doi.org/10.1016/S0958-2118(02)08034-5

[8] Polettini, A., Pomi, R., Stramazzo, A. (2016). $\mathrm{CO}_{2}$ sequestration through aqueous accelerated carbonation of BOF slag: A factorial study of parameters effects. Journal of Environmental Management, 167: 185-195. https://doi.org/ 10.1016/j.jenvman.2015.11.042

[9] Asi, I.M. (2007). Evaluating skid resistance of different asphalt concrete mixes. Building \& Environment, 42(1): 325-329. https://doi.org/10.1016/j.buildenv.2005.08.020

[10] Kourounis, S., Tsivilis, S., Tsakiridis, P.E., Papadimitriou, G.D., Tsibouki, Z. (2007). Properties and hydration of blended cements with steelmaking slag. Cement \& Concrete Research, 37(6): 815-822. https://doi.org/10.1016/j.cemconres.2007.03.008 
[11] Manso, J.M., Polanco, J.A., Losañez, M., González, J.J. (2006). Durability of concrete made with EAF slag as aggregate. Cement \& Concrete Composites, 28(6): 528534. https://doi.org/10.1016/j.cemconcomp.2006.02.008

[12] Monshi, A., Asgarani, M.K. (1999). Producing Portland cement from iron and steel slags and limestone. Cement \& Concrete Research, 29(9): 1373-1377. https://doi.org/10.1016/S0008-8846(99)00028-9

[13] Yüksel, İ. (2018). A review of steel slag usage in construction industry for sustainable development. Environment Development \& Sustainability, 19(2): 1-16. https://doi.org/10.1007/s10668-016-9 759-x

[14] Maslehuddin, M., Sharif, A.M., Shameem, M., Ibrahim, M., Barry, M.S. (2003). Comparison of properties of steel slag and crushed limestone aggregate concretes. Construction \& Building Materials, 17(2): 105-112. https://doi.org/10.1016/S0950-0618(02)00095-8

[15] Beshr, H., Almusallam, A. A., Maslehuddin, M. (2003). Effect of coarse aggregate quality on the mechanical properties of high strength concrete. Construction \& Building Materials, 17(2): 97-103. https://doi.org/10.1016/S0950-0618(02)00097-1

[16] Chukwudi, B.C., Okorie, B.A. (2014). Evaluation of the physical and mechanical properties of ceramic tiles processed using steel slag. Advanced Materials Research, 856: 257-261. https://doi.org/10.4028/www.scientific.net/AMR.856.25 7
[17] Ortiz, N., Pires, M.A., Bressiani, J.C. (2001). Use of steel converter slag as nickel adsorber to wastewater treatment Waste Management, 21(7): 631-635. https://doi.org/10.1016/S0956-053X(00)00123-9

[18] Hou, P.K., Kawashima, S., Kong, D.Y., Corr, D.J., Qian, J.S., Shah, S.P. (2013). Modification effects of colloidal nanoSiO2 on cement hydration and its gel property. Composites Part B Engineering, 45(1): 440-448. https://doi.org/10.1081/LESA-200034837

[19] Ma, X., Ni, W., Liu, X. (2016). Experimental study on performance optimization of steel slag powder and preparation of non-clinker concrete. Materials Review. https://doi.org/10.11896/j.issn.1005-023X.2016.16.029

[20] Wu, H., Ni, W., Cui, X.W., Wang, S. (2014). Preparation of concrete sleeper using hot steaming steel slag with low autogenous shrinkage. Transactions of Materials \& Heat Treatment, 35(4): 7-12. https://doi.org/10.13289/j.issn.1009-6264.2014.04.002

[21] Okhuysen, W., Gassaway, J.D. (1995). Particle size distribution instrument. Topical report 13. Office of Scientific \& Technical Information Technical Reports. Diagnostic Instrumentation and Analysis Laboratory, 4. https://doi.org/10.2172/39146

[22] Hou, P., Kawashima, S., Kong, D., Corr, D.J., Qian, J.S., Shah, S.P. (2013). Modification effects of colloidal nanoSiO 2 on cement hydration and its gel property. Composites Part B Engineering, 45(1): 440-448. https://doi.org/10.1016/j.compositesb.2012.05.056 